\title{
Coacervation in aqueous solutions of short chain tetraalkylammonium bromide and sodium silicate
}

\section{Citation for published version (APA):}

Donck, van der, J. C. J., \& Stein, H. N. (1993). Coacervation in aqueous solutions of short chain tetraalkylammonium bromide and sodium silicate. Langmuir, 9(9), 2270-2275.

https://doi.org/10.1021/la00033a005

DOI:

10.1021/la00033a005

Document status and date:

Published: 01/01/1993

\section{Document Version:}

Publisher's PDF, also known as Version of Record (includes final page, issue and volume numbers)

\section{Please check the document version of this publication:}

- A submitted manuscript is the version of the article upon submission and before peer-review. There can be important differences between the submitted version and the official published version of record. People interested in the research are advised to contact the author for the final version of the publication, or visit the $\mathrm{DOI}$ to the publisher's website.

- The final author version and the galley proof are versions of the publication after peer review.

- The final published version features the final layout of the paper including the volume, issue and page numbers.

Link to publication

\section{General rights}

Copyright and moral rights for the publications made accessible in the public portal are retained by the authors and/or other copyright owners and it is a condition of accessing publications that users recognise and abide by the legal requirements associated with these rights.

- Users may download and print one copy of any publication from the public portal for the purpose of private study or research.

- You may not further distribute the material or use it for any profit-making activity or commercial gain

- You may freely distribute the URL identifying the publication in the public portal.

If the publication is distributed under the terms of Article 25fa of the Dutch Copyright Act, indicated by the "Taverne" license above, please follow below link for the End User Agreement:

www.tue.nl/taverne

Take down policy

If you believe that this document breaches copyright please contact us at:

openaccess@tue.nl

providing details and we will investigate your claim. 


\title{
Coacervation in Aqueous Solutions of Short Chain Tetraalkylammonium Bromide and Sodium Silicate
}

\author{
J. C. J. van der Donck and H. N. Stein* \\ Laboratory of Colloid Chemistry and Thermodynamics, Einhoven University of Technology, \\ P.O. Box 513, NL-5600 MB Eindhoven, The Netherlands
}

Received November 5, 1992. In Final Form: June 3, 1993

\begin{abstract}
Coacervation (liquid/liquid separation) takes place in aqueous solutions containing short chain tetraalkylammonium (TAA) and silicate ions when other ions $\left(\mathrm{Na}^{+}, \mathrm{Br}\right)$ are present. The TAA bromide is predominantly present in the upper layer and the sodium silicate is mainly present in the lower layer. The coacervation can be described using the activity coefficients of the two separate salts and a RedlichKister type excess Gibbs free energy. Since part of the Gibbs free energy is dependent on the enthalpy of hydrophobic hydration of the TAA ions, the driving force for coacervation is ascribed to a mismatch of the hydration layers around the silicate and TAA ions.
\end{abstract}

\section{Introduction}

In the early literature coacervation (separation into two aqueous phases) was mostly reported to occur in the presence of colloids. These colloids are usually proteins or macromolecules, as gelatin or casein with sulfates, ${ }^{1}$ but coacervation can also take place in ionic systems. According to $\mathrm{Kruyt}^{2}$ two types of coacervation are observed: simple and complex coacervation. Coacervation is called simple coacervation when the phase separation is induced by the nonionized groups in the solute molecules. This type of coacervation is a kind of segregation, since it is characterized by a water deficit in the total system. Upon dilution the coacervate disappears. Complex coacervation is induced by the interactions between ionized groups. It occurs when a second colloidal species is added to a solution of a charged colloid, which is oppositely charged to the one being added. The charges on the macromolecules induce the formation of salt bonds. Voorn ${ }^{3}$ described complex coacervation of polyelectrolytes in terms of electrostatic interactions and entropy. In both coacervate types lyophilic colloids are involved.

Coacervation can take place also in aqueous solutions of low molecular organic solutes. The coacervation in aqueous solutions of organic ionic compounds has been studied by Mugnier de Trobriand et al. and Lucas et al. ${ }^{4-9}$ They found that aqueous solutions of tetraalkylammonium (TAA) halides of sufficient chain length separate into two aqueous layers at high concentration and that these coacervates can be used for the extraction of inorganic ions and ion complexes such as $\mathrm{UO}_{2}{ }^{2+}$. Coacervation in these systems was thought to be due to simple coacervation. They supposed that the demixing was caused by the limited amount of water. At high concentrations, formation of dimers and micelles of TAA ions was assumed to take place. The amount of water in hydration shells around the dissolved species diminishes and the water coming free can be used to dissolve other ions. In this way two

(1) Pauli, W. Kolloidchem. Beih. 1912, 3, 382.

(2) Kruyt, H. R. Colloid Science; Elsevier Publishing Co.: Amsterdam, 1949; Volume II, pp 243-256.

(3) Voorn, M. J. Complex coacervation. Ph.D. Thesis, Utrecht, 1956. (4) Mugnier de Trobriant, A. M.; Lucas, M.; Steigman, J.; Hwang, L. J. Inorg. Nucl. Chem. 1979, 41, 1214.

(5) Mugnier de Trobriant, A. M.; Lucas, M.; Steigman, J.; Hwang, L. J. Phys. Chem. 1987, 82, 418.

(6) Mugnier de Trobriant, A. M. Centre d'Etudes Nucleaires de Fontenay-aux-Roses, Rapport CEA-R-5009, 1979.

(7) Lucas, M. J. Inorg. Nucl. Chem. 1970, 32, 3692.

(8) Lucas, M. J. Inorg. Nucl. Chem. 1971, 33, 543.

(9) Lucas, M. J. Inorg. Nucl. Chem. 1971, 33, 1883. kinds of regions are formed, one with the quaternary ammonium compound and one with the other salt. Quantitative support for this theory was not advanced however. Other ionic systems in which coacervation takes place are surfactant systems. Several investigators have studied the solution properties of a number of coacervating anonic and cationic soap systems extensively. $2,10,11$ These systems are mainly classified as simple coacervation.

Thalberg et al..$^{12-15}$ investigated coacervation by interactions between polymers and oppositely charged surfactants. Because of the electrostatic interactions and the interactions between the hydrophobic parts of the polymer and the surfactant, a special phase separation behavior occurs. Although only one type of polymer is present, this is an example of complex coacervation in ionic systems. This might lead to the conclusion that coacervation in systems of TAA bromide-sodium silicate-water could be due to complex coacervation, since dissolved silicate ions can be considered partially as a small type of inorganic polymer and the quaternary ammonium ions mostly have surface active properties.

We found coacervation in solutions containing sodium silicate and quaternary ammonium bromide starting from tetramethylammonium (TMA). Previously reported data $^{4-9}$ refer only to quaternary ammonium ions with larger alkyl groups. In the present paper the formation of a coacervate is reported in TMA bromide solutions with sodium silicate salts but not with other sodium salts $\left(\mathrm{Cl}^{-}\right.$, $\left.\mathrm{Br}-, \mathrm{NO}_{3}^{-}, \mathrm{SO}_{4}{ }^{2-}\right)$ up to saturation. No coacervation was observed by us for systems which contain sodium bromidesodium silicate, TMA bromide-TMA silicate, TMA bromide-sodium bromide, or TMA silicate-sodium silicate. For coacervation to occur in aqueous solutions containing small chain TAA and silicate ions, the presence of additional ions appears to be necessary (in our case, sodium and bromide). These phenomena suggest that interactions between TAA and silicate are the cause of the demixing behavior. In viscosity measurements ${ }^{16}$ a distorted ion cloud was found in solutions of TMA silicates. This

(10) Vassiliades, A. E.; Cohen, I. J. Am. Oil Chem. Soc. 1962, 39, 246. 1829 .

(12) Thalberg, K.; Lindman, B. J. Phys. Chem. 1989, 93, 1478.

(13) Thalberg, K.; Lindman, B.; Karlström, G. J. Phys. Chem. 1990 , 94,4289 .

(14) Thalberg, K.; Lindman, B. Langmuir 1991, 7, 277.

(15) Thalberg, K.; Lindman, B.; Karlström, G. J. Phys. Chem. 1991, 95,3370 .

(16) van der Donck, J. C. J.; Stein, H. N. Langmuir, in press. 
indicates the presence of an additional interaction between these ions which can be the leading cause of the coacervation. In the present paper the distribution of the ions between the two layers will be discussed and the coacervation will be described in thermodynamic parameters.

\section{Theory}

For a description of coacervation two questions arise: (i) how are the ions distributed over the two aqueous layers and (ii) in what concentration range does the demixing take place.

The distribution can be expressed in terms of the distribution coefficient used by Mugnier de Trobriant and Lucas $^{4-9}$

$$
D=c_{\mathrm{u}} / c_{1}
$$

In which $D$ is the distribution coefficient and $c_{u}$ and $c_{1}$ are the concentrations in upper and lower phases, respectively.

For the description the concentrations of all compounds (in this case six, viz. $\mathrm{TAA}^{+}, \mathrm{BR}^{-}, \mathrm{Na}^{+}, \mathrm{SiO}_{2}, \mathrm{OH}^{-}, \mathrm{H}_{2} \mathrm{O}$ ) must be known in all phases (two). This does complicate the understanding of the system. The system can be simplified to three compounds by treating the system as a ternary system of two salts and water. The salts should be formed by the ions which show comparable distribution over the two layers. Because of the formation of two aqueous layers, coacervation can be regarded as a mixture of two partially miscible fluids. Therefore theories about partial miscibility will be used to describe the coacervation.

Demixing phenomena can be described with the Gibbs free energy of solutions. The coacervation is caused by an excess Gibbs free energy, $G^{\mathrm{E}}$. From viscosity measurements $^{16}$ it is known that a repulsion between TAA and silicate ions is superimposed on the electrostatic attraction. Therefore the physical interpretation of the excess Gibbs free energy is thought to be an interaction between the TAA and silicate ions. The excess Gibbs free energy can be described with the Redlich-Kister equation (eq 2). ${ }^{17}$

$$
G^{\mathrm{E}}=x_{2} x_{3}\left(E_{0}+\left(x_{2}-x_{3}\right) E_{1}+\left(x_{2}-x_{3}\right)^{2} E_{2}+\ldots\right)
$$

In the first instance only two terms are taken into account. The Gibbs free energy can be written as

$$
\begin{array}{r}
G=x_{1} \mu_{1}^{0}+x_{2} \mu_{2}^{0}+x_{3} \mu_{3}^{0}+R T\left\{x_{1} \ln x_{1}+x_{2} \ln x_{2}+\right. \\
\left.x_{3} \ln x_{3}\right\}+x_{2} x_{3}\left(E_{0}+\left(x_{2}-x_{3}\right) E_{1}\right)+G^{\gamma}
\end{array}
$$

A physical interpretation of the parameters $E_{0}$ and $E_{1}$ in this equation will be given in the discussion section. In this equation $\mu_{i}{ }^{\circ}$ is the thermodynamic potential of species $i$ in the standard state (e.g., at an activity of 1 ), $x_{i}$ is the molar fraction, and $G^{\gamma}$ is the contribution of the activity coefficients. Molar fractions are usually referring to nonelectrolytes. In the present work the molar fractions have to be defined such as to take into account the dissociation of the electrolytes. The molar fraction becomes

$$
x_{\mathrm{i}}=\frac{\nu_{\mathrm{i}} n_{\mathrm{i}}}{\sum_{i=1}^{3} \nu_{\mathrm{i}} n_{\mathrm{i}}}
$$

$n_{i}$ is the amount of compound $i$ present (in moles) and $\nu_{i}$ the number of ions in one mole $i$.

The parameters $E_{0}$ and $E_{1}$ in eq 3 can be found from the plait point as follows: The plait point is often situated

(17) Redlich, O.; Kister, A. T. Ind. Eng. Chem. 1948, 40, 345. on the line through the mid points of the conodes. 18 In ternary systems the analytical criteria for the binodal are more complicated than for binary systems. By treating the system as a quasi-binary system it is easier to define these criteria. For reducing the ternary system to a binary system, we draw a tangential on the $\mathrm{L}_{1}-\mathrm{L}_{2}$ binodal line passing through the plait point. The tangential concerned is regarded as a line from the binary mixture of components 1 and 2 with molar fraction $x_{2}=x_{2,0}$ to the binary mixture of 1 and 3 with molar fraction $x_{3}=x_{3,0}$. This line can be described in parameter form

$$
x_{1}=1-x_{2,0}+i\left(x_{2,0}-x_{3,0}\right) ; \quad x_{2}=(1-i) x_{2,0} ; \quad x_{3}=i x_{3,0}
$$

In this description $i$ is the distance parameter with values between 0 and 1 .

On that line the second derivative of the $G$ function to the composition coordinate is zero at the plait point because the plait point is on the spinodal. For lines parallel to the tangential but at higher electrolyte concentration, two bending points in the $G$ curve are found. At lower electrolyte concentrations no bending point is present in the $G$ curve. Therefore the second derivative must have an extreme at the plait point and the third derivative has to be zero too.

After substitution of the composition in parameter form (according to eq 5 ) in eq $3, E_{1}$ can be determined with the help of the third derivative of the Gibbs free energy and the plait point

$$
\frac{E_{1}}{R T}=\frac{\frac{\left(x_{2,0}-x_{3,0}\right)^{3}}{x_{1}{ }^{2}}-\frac{x_{2,0}{ }^{3}}{x_{2}{ }^{2}}+\frac{x_{3,0}{ }^{3}}{x_{3}{ }^{2}}-\frac{\mathrm{d}^{3} G^{\gamma}(i)}{R T \mathrm{di}^{3}}}{6\left(x_{2,0}{ }^{2} x_{3,0}+x_{2,0} x_{3,0}{ }^{2}\right)}
$$

In this equation $x_{1}, x_{2}$, and $x_{3}$ are the molar fractions in the plait point. $x_{2,0}$ and $x_{3,0}$ have been defined previously; $\mathrm{d}^{3} G^{\gamma}(i) / \mathrm{d} i^{3}$ is the third derivative of the contribution of the activity coefficienty to the Gibbs free energy. The $E_{1}$ calculated with eq 6 can be used to calculate the $E_{0}$ from the second derivative of the Gibbs free energy:

$$
\begin{aligned}
\frac{E_{0}}{R T}=\frac{\frac{\left(x_{2,0}-x_{3,0}\right)^{2}}{x_{1}}+\frac{x_{2,0}}{x_{2}}+\frac{x_{3,0}{ }^{2}}{x_{3}}+\frac{\mathrm{d}^{2} G^{\gamma}(i)}{R T \mathrm{di}^{2}}}{2\left(x_{2,0} x_{3,0}\right)}- \\
\frac{\left(6 x_{3} x_{2,0}\left(x_{2,0}+x_{3,0}\right)-2 x_{2,0} x_{3,0}\left(2 x_{2,0}+x_{3,0}\right)\right) \frac{E_{1}}{R T}}{2\left(x_{2,0} x_{3,0}\right)}
\end{aligned}
$$

When the values of $E_{0}$ and $E_{1}$ are known, all important constants of eq 3 except for the contribution of the activity coefficients are known. The contributions of the activity coefficients of the separate salts to the Gibbs free energy can be incorporated in several ways. The best way is splitting the activity coefficients into their various contributions:

$$
\log \gamma_{ \pm \mathrm{i}}=A I^{1 / 2}+B I+R\left(m_{i}\right)
$$

In this equation, $I$ is the total ionic strength, $m_{i}$ is the molality of component $i, A$ is the Debye-Hückel limiting slope, $B$ takes into account the effects of incomplete hydration, and $R\left(m_{i}\right)$ is an additional function which describes other contributions to the activity coefficient, such as association. The Debye-Hückel effect and the contribution of incomplete hydration are dependent on

(18) Robbins, L. A. Liquid-liquid extraction: In Perry, R. H., Green, D. W., Maloney, J. O., Eds.; Perry's Chemical Engineers' Handbook, 6th ed.; 1984; p 156. 
the total ionic strength. The residual function $R\left(m_{i}\right)$ can approximately be considered as dependent on the molality of component $i$ only. The complete contributions of the activity coefficients to the Gibbs free energy can be expressed as

$$
G^{\gamma}=2.303 R T \sum_{i=2}^{3}\left\{-x_{i}\left(A_{i} I^{1 / 2}+B_{i} I+R_{i}\left(m_{i}\right)\right)\right\}
$$

The Debye-Hückel limiting slope is theoretically known. By using literature activity coefficients the $B$ and $R$ values can be determined.

\section{Experimental Section}

Materials used were as follows: sodium silicate solution, den Hertog, $10.1 \% \mathrm{NaOH}, 27.8 \% \mathrm{SiO}_{2}$; sodium hydroxide, Merck, Pro Analysi; sodium hydroxide, Merck Titrisol $0.1 \mathrm{M}$ and $1 \mathrm{M}$; sodium tetraphenylborate, Janssen Chimica, $98 \%$; TMA bromide, Merck, $>99 \%$; TMA bromide, Janssen, $>99 \%$; tetraethylammonium (TEA) bromide, Merck, $>99 \%$; tetrapropylammonium (TPA) bromide, Janssen, $>98 \%$; TPA bromide, Merck, $>99 \%$; silver nitrate, Merck Titrisol, $0.1 \mathrm{M}$; silicium tetrachloride in sodium hydroxide, Merck Titrisol, $1 \mathrm{~g} / \mathrm{mL}$; nitric acid, Merck, $65 \%$; ammonium heptamolybdate, Merck, Pro Analysi, >99\%; twice distilled water. Silicate and their aqueous solutions will be indicated by their metal ion to silicon molar ratio. Thus, a 2:1 sodium silicate has a $\mathrm{Na}: \mathrm{Si}$ molar ratio of $2: 1$.

Procedure for the Determination of Distribution Coefficients. Coacervates were prepared with constant TAA bromide/sodium silicate ratio but different water contents. The coacervates were shaken overnight at $25^{\circ} \mathrm{C}$. The phases were separated and the density was determined by weighing a known volume. TAA and bromide concentrations were determined using an Orion autochemistry system $940 / 960$. For the TAA concentration a potentiometric titration with sodium tetraphenylborate and a TAA-sensitive electrode, developed by Holten and Stein, ${ }^{19}$ was used. The bromide was determined by a potentiometric titration with silver nitrate and a Philips bromide sensitive electrode (IS 550). Sodium concentrations were determined with AES (Perkin-Elmer 4995 AA spectrophotometer). Silicate concentrations were determined with the molybdate method. The following procedure was used for the molybdate method:20 $1 \mathrm{~mL}$ of silicate solution $\left(0-50 \mathrm{mg} / \mathrm{L} \mathrm{SiO}_{2}\right)$ was added to $2 \mathrm{~mL}$ of molybdate solution ( $8 \%$ ammonium molybdate, $4 \%$ sodium hydroxide) and $1 \mathrm{~mL}$ of nitric acid (20\%). A yellow compound was formed. After $13 \mathrm{~min}$ the extinction was measured at 370 nm with a Zeiss spectrophotometer MM12, PMQ II.

Procedure for the Determination of the Binodal. The binodal was determined with a titration procedure. An amount of quaternary ammonium bromide was dissolved in an amount of sodium silicate solution, with known concentration, until a coacervate was formed. The stirred coacervate was opaque. Water was added until the opaqueness disappeared. The limit of the coacervation region at a given $\mathrm{TAA}$ bromide/sodium silicate ratio was taken to be that composition where coacervate becomes transparent upon addition of one droplet of water. By weighing the solution the amount of added water was determined. By addition of new quaternary ammonium bromide to that solution, a coacervate was formed again and water was added until the coacervate disappeared. This method was repeated several times. A large part of the binodal can be determined in this way. All experiments were carried out at room temperature.

This procedure was performed with several kinds of sodium silicate solutions and TAA bromides. For TMA bromide five sodium/silicate ratios were used, 0.82:1, 1:1, 1.5:1, 2:1, 3:1, and for TEA and TPA bromide a $2: 1$ sodium/silicate ratio.

The silicate solution was prepared by adding sodium hydroxide (Merck Titrisol) to a sodium silicate (den Hertog) solution until the desired sodium/silicate ratio was obtained.

\section{Results}

In Figure 1 the distribution coefficients are shown of coacervates of TMA bromide and sodium silicate with

(19) Holten, C. L. M.; Stein, H. N. Analyst 1990, 115, 1211.

(20) Kato, K. Anal. Chim. Acta 1976,82,401. Truesdale, V. W.; Smith, C. J. Analyst 1975, 100, 797

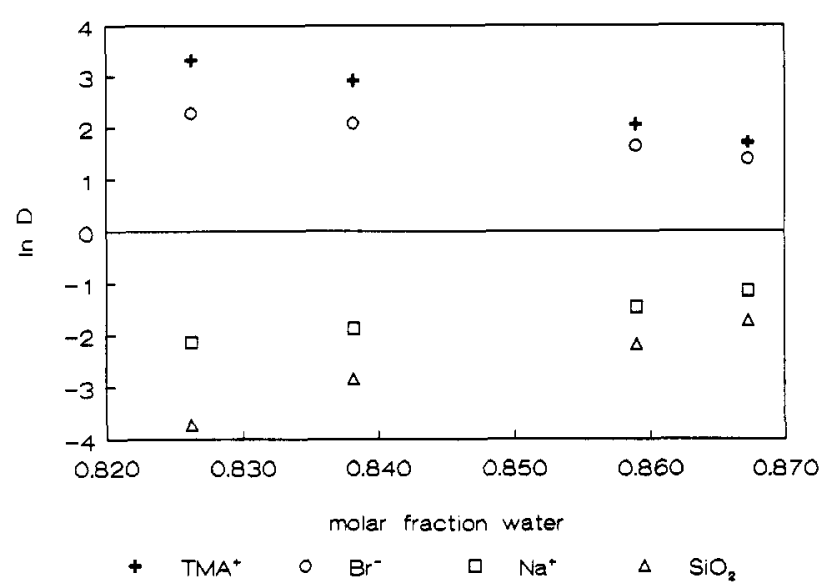

Figure 1. Distribution coefficients of TMA bromide and sodium silicate (2:1).

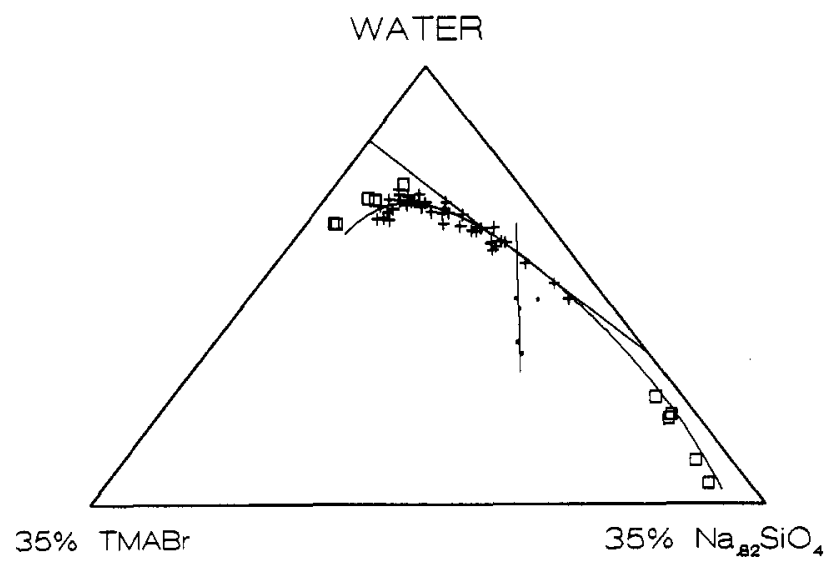

Figure 2. Experimental (+ titration method, $\square$ distribution) and calculated binodal $(-)$ of the coacervate TMA bromidesodium silicate $(0.82: 1)$.

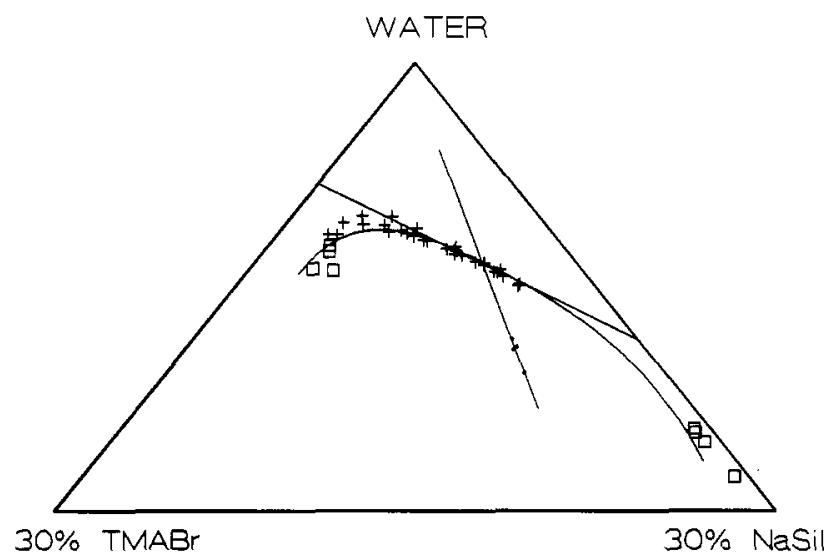

Figure 3. Experimental and calculated binodal of the coacervate TMA bromide-sodium silicate (1:1). Symbols as in Figure 2.

sodium to silicate ratio of $2: 1$. The distribution coefficients of the other systems investigated show comparable behavior.

A complete analysis of the two coexisting layers was carried out in order to express the compositions of these layers in molar fractions of TAA bromide, sodium silicate, and water. With the titration procedure the binodal can be determined and the intersection point of the line through the midpoints of the conodes and the binodal yields the plait point. In Figures 2-6 the data on binodal compositions are shown. The straight lines are the line through the midpoints of the conodes and the tangent on the binodal in the plait point. From this tangent and the position of the plait point, the $E_{0}$ and $E_{1}$ are calculated with eqs 6 and 7 . In Table I the positions of the plait 


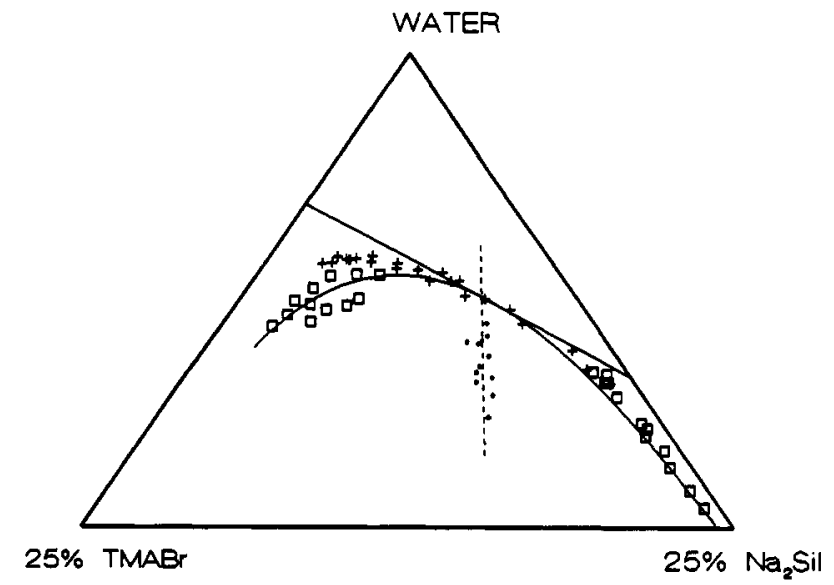

Figure 4. Experimental and calculated binodal of the coacervate TMA bromide-sodium silicate (2:1). Symbols as in Figure 2.

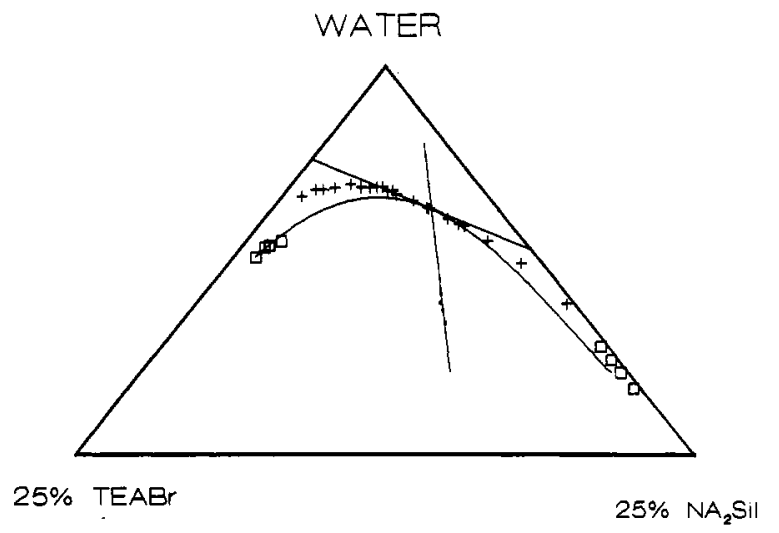

Figure 5. Experimental and calculated binodal of the coacervate TEA bromide-sodium silicate (2:1). Symbols as in Figure 2.

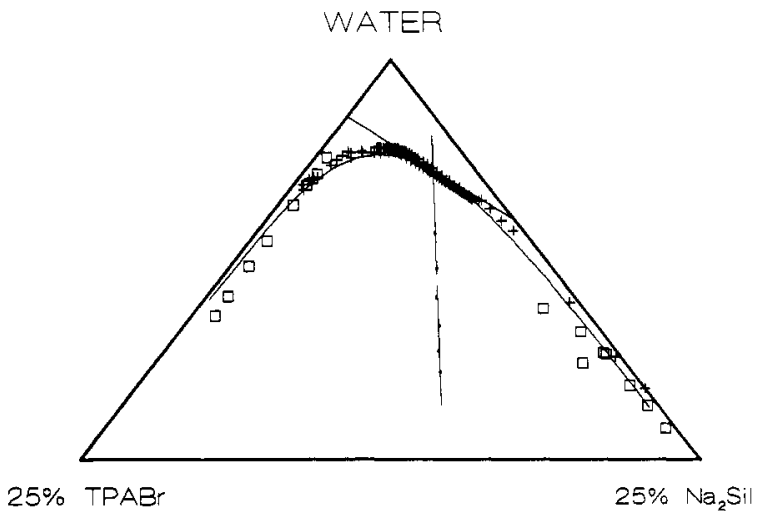

Figure 6. Experimental and calculated binodal of the coacervate TPA bromide-sodium silicate (2:1). Symbols as in Figure 2.

points and the calculated values of the $E_{0}$ and $E_{1}$ are listed for the coacervates investigated.

\section{Discussion}

In all cases the quaternary ammonium bromide was mainly dissolved in the upper phase and the sodium silicate was present in the lower phase. The system can be described as a ternary system TAA bromide/sodium silicate/water. As is to be expected the distribution coefficients show a tendency toward unity at higher molar fractions of water.

The driving force for coacervation can be evaluated from the following facts: (a) The presence of both TAA and silicate ions is necessary for coacervation. This has, strictly speaking, been shown only in the case of TMA but is probable also for TEA and TPA as cations. (b) No coacervation is found in TAA silicate solutions in the absence of other ions. (c) On phase separation, TAA and silicate ions are found predominantly in different liquid phases. Statement a indicates a special type of interaction between TAA and silicate ions as the important factor for coacervation. This may be a repulsion or an attraction. Statement $c$ implies that there is a decrease in Gibbs free energy on separating a mixture of TAA, silicate, $\mathrm{Na}^{+}$, and $\mathrm{Br}$ ions into pairs $\mathrm{TAA}+\mathrm{Br}^{-}$and $\mathrm{Na}^{+}+$silicate. This means that the special type of interaction between TAA and silicate ions is repulsive rather than attractive. Such a repulsion is superimposed on the normal attraction between oppositely charged ions: coacervation occurs only when other ions are present for compensation of the charges on TAA and silicate ions, respectively. This is in agreement with viscosity measurements. ${ }^{16}$

In the thermodynamic description the contribution of the activity coefficients has to be taken into account. For the activity coefficients of the TAA bromide literature data were provided by Wirth ${ }^{21}$ and Lindenbaum and Boyd. ${ }^{22}$ Activity coefficients of sodium silicates are not available. As an approximation activity coefficients of other sodium salts were used reported by Robinson and Stokes. ${ }^{23}$ For the sodium silicate with a sodium/silicate ratio of $2: 1$, activity coefficients of sodium sulfate were used because of the resemblance between silicate and sulfate in charge and structure. For the sodium silicates with ratios $0.82: 1$ and 1:1 activity coefficients of sodium chloride were used. In the solutions of sodium silicate with ratio $0.82: 1$ the total charge on the silicates is lower than in sodium silicate (1:1 ratio) solutions. In view of the Debye-Hückel limiting slope being proportional to $\left|z_{+} z_{-}\right|$ and the average charge of the silicate ions being -0.82 in this particular case, the Debye-Hückel limiting slope for this ratio should be multiplied with this charge. The $B$ and $R$ terms were estimated by the sodium chloride values.

Figure 7 shows an example of the contributions of the activity coefficients and the second and third derivative along the tangential through the plait point for TMA bromide-sodium silicate (ratio 2:1) as calculated according to eq 9. At the plait point the activity coefficient of TAA bromide was calculated as 0.22 and for sodium silicate a value of 0.06 was obtained. For other systems comparable values were calculated.

In this figure the place of the plait point is shown by the vertical line at $i=0.55$. The values of the second and third derivative are used to calculate $E_{0}$ and $E_{1}$ from eq 6 and 7. This kind of calculation is performed for all coacervates.

Of course taking the activity coefficients of sodium salts other than sodium silicate gives only an approximation of the contribution of the activity coefficients to the Gibbs free energy. Nevertheless, this taking into account the activity coefficients approximately is better than ignoring them.

When the $E_{0}$ and $E_{1}$ are known the binodals can be calculated. For most coacervates the calculated binodal gives a satisfactory comparison with the experiments. Deviations are seen in Figures 4 and 5 for TMA bromide and TEA bromide 2:1 sodium silicate coacervates. For these systems the binodals found with the titration method are at much higher water contents at the TAA bromide side of the diagram than the composition of the upper layer. This is ascribed to the fact that the systems are considered to be ternary systems. This implies the assumption that the cations and anions assigned to a

(21) Wirth, H. J. Phys. Chem. 1967, 71, 2922.

(22) Lindenbaum, S.; Boyd, G. E. J. Phys. Chem. 1964, 68, 911.

(23) Robinson, R. L.; Stokes, R. H. Electrolyte solutions, 2nd ed. Butterworths Scientific Publications: London, 1959. 
Table I. Plait Points and Constants of the Excess Gibbs Free Energy

\begin{tabular}{|c|c|c|c|c|c|c|}
\hline \multicolumn{2}{|c|}{ sample } & \multicolumn{3}{|c|}{ plait point } & \multicolumn{2}{|c|}{ excess constants } \\
\hline TAA Br & $\mathrm{Na} / \mathrm{SiO}_{2}$ ratio & $x_{1}$ water & $x_{2}$ TAABr & $\overline{x_{3} \mathrm{Na}_{x} \mathrm{Sil}}$ & $\overline{E_{0}, \mathrm{~kJ} / \mathrm{mol}^{2}}$ & $E_{1}, \mathrm{~kJ} / \mathrm{mol}^{3}$ \\
\hline TMA & $0.82: 1$ & 0.8505 & 0.0284 & 0.1211 & 43.15 & 13.43 \\
\hline TMA & 1:1 & 0.8652 & 0.0393 & 0.0955 & 32.89 & 17.87 \\
\hline TMA & $2: 1$ & 0.8725 & 0.0356 & 0.0919 & 29.06 & 19.72 \\
\hline TEA & $2: 1$ & 0.9082 & 0.0272 & 0.0646 & 38.35 & 52.54 \\
\hline TPA & $2: 1$ & 0.9311 & 0.0173 & 0.0516 & 37.61 & 141.02 \\
\hline
\end{tabular}

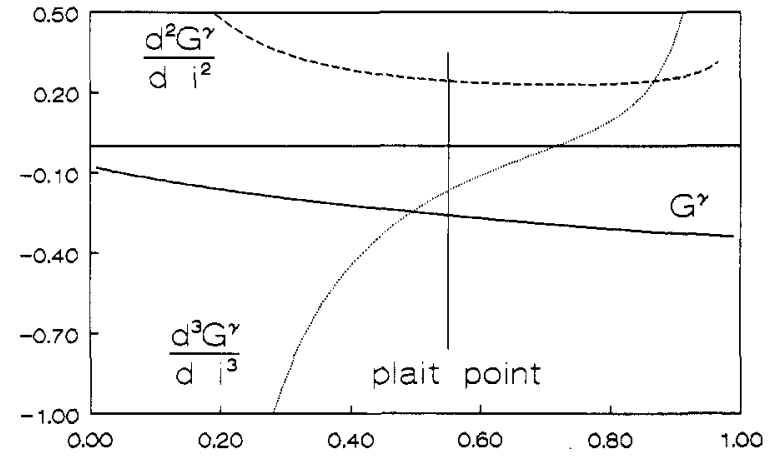

Figure 7. Contributions of the activity coefficients along the tangential on the binodal through the plait point for TMA bromide-sodium silicate $(2: 1)$.

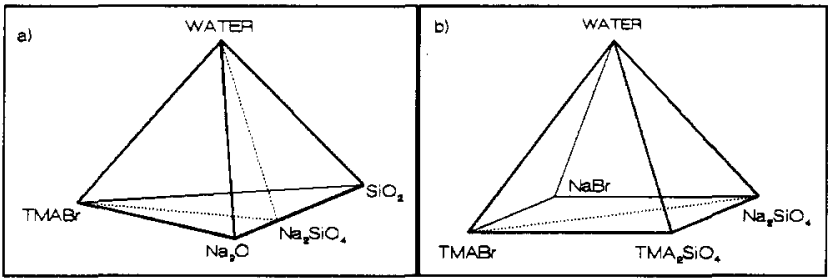

Figure 8. Possible quaternary and quinary representations of the investigated systems.

particular electrolyte distribute themselves over the coexisting phases in the same way; the titration method gives the binodal for the ternary systems. The compositions of both layers are not ternary, however, and the deviations from the ternary model can be described by two different methods (see Figure 8). Alternatively, the system can be considered as a quaternary system of water, TAA bromide, sodium hydroxide, and silica (model $i$, see Figure 8a). Deviations from the ternary system can result if different sodium/silicate ratios exist in the upper and lower phases, respectively. The average charge of the silicate ions in the upper layers is different from that in the lower layer, but the TMA and the bromide are distributed in exactly the same way within both layers in this description. The system can also be considered as a quinary system of water, TAA bromide, TAA silicate, sodium bromide, and sodium silicate (model ii, see Figure $8 \mathrm{~b})$. Deviations from the quinary system can occur when sodium ions are exchanged by TAA ions in one of the layers. The mean charge of the silicate ions is the same in both layers, in this model.

The influence of these processes is most clearly evident from the distribution coefficients. If demixing occurs according to the ternary system TAA bromide-sodium silicate-water, the distribution coefficients of TMA would equal those of bromide and the distribution coefficients of sodium would equal those of silicate in model $i$; the distribution coefficients of TAA and bromide should have the same value, but the distribution coefficients of sodium and silicate may however be different. In process ii all the distribution coefficients may be different. A simple test exists of whether or not the description as process ii may be applied. If the distribution coefficients of TAA are larger than those of bromide, the distribution coefficients of silicate should be larger than those of sodium. The difference between the amount of TAA and bromide present in one layer should be compensated by a comparable additional amount of silicate or sodium ions. In process ii the hydroxide should be distributed in the same way as the silicate, since the average charge of the silicate is assumed to be equal in two coexisting phases. However there is no reason why the silicate and the hydroxide should distribute the same way. In most cases the distribution coefficients of TMA and bromide are different. This shows that process $i$ is inadequate, which suggests, that the system should be treated according to process ii at least. For coacervates with TEA and TPA the test does not exclude process $\mathrm{ii}$, but the difference in TAA and bromide concentration is not equal to the difference in sodium and silicate concentration. From the electroneutrality condition the concentrations of hydroxylic ions can be calculated. In most cases different silicate/hydroxylic ratios for the two layers are found, which suggests that process ii in itself cannot completely describe the phenomena but that a combination of processes $i$ and ii should be considered. In these coacervates the formation of double ring silicate ions, as reported by Hoebbel et al., ${ }^{24-26}$ interferes with processes $i$ and ii. As double ring formation occurs mainly in the upper layer, the distribution coefficients of silicate are in those cases larger than those corresponding to the monomers. Therefore both processes $i$ and $i$ and the formation of double ring silicate ions influence the deviations from the ternary systems TAA bromide-sodium silicate-water. The predominant formation of double ring structures in the upper layer strongly suggests that this double ring formation is promoted by the interaction between hydrophobically hydrated regions around alkyl chains and hydrophobically hydrated regions around $\equiv \mathrm{Si}-\mathrm{O}-\mathrm{Si} \equiv$ groups (to be distinguished from hydrophilically hydrated $\equiv \mathrm{Si}-\mathrm{OH}$ or $\mathrm{Si}-\mathrm{O}^{-}$groups). This will be treated in more detail in a separate paper. ${ }^{27}$

The excess Gibbs free energy is approximated with the Redlich-Kister equation (see eq 2). This equation is usually employed for nonelectrolytes but can be used for electrolyte solutions when interactions are considered that are not primarily electrostatic. It has been remarked that the coacervation is caused by an interaction between TAA and silicate ions. These ions are found predominantly in different phases, electrostatic interactions cannot be the cause of coacervation, and therefore the Redlich-Kister equation can be applied.

In many cases the excess enthalpy and entropy have the same sign while the absolute values of the interaction enthalpy and the excess entropy (more strictly $\mathrm{Ts}^{\mathrm{E}}$ ) are about the same. However in some mixtures of polar and apolar compounds the excess entropy can be very small

(24) Hoebbel, D.; Garzó, G.; Engelhardt, G.; Vargha, A. Z. Anorg. Allg. Chem. 1982, 494, 31 .

(25) Hoebbel, D.; Vargha, A.; Fahlke, B.; Engelhardt, G. Z. Anorg. Allg. Chem. 1984, 509, 85.

(26) Hoebbel, D.; Vargha, A.; Engelhardt, G.; Ujsź́szy, K. Z. Anorg. Allg. Chem. 1985, 521, 61 .

(27) van der Donck, J. C. J.; Vaessen, G. E. J.; Stein, H. N. Submitted to Langmuir. 
or even negative, while the excess enthalpy is positive. ${ }^{28}$ This is considered to be due to the formation of networks of hydrogen bonds. In our case we are dealing with hydrophobically and hydrophilically hydrated ions, and it is likely that these hydrated regions are still present in the mixtures. If so $H^{\mathrm{E}}$ will be positive because in a mixture a part of the sodium ions near silicate ions is replaced by TAA ions, and part of the bromide ions near TAA ions are replaced by silicate ions. The positive $H^{\mathrm{E}}$ is then caused by the larger average distance between cations and anions in the mixture, than in the separate solutions of sodium silicate and TAA bromide. It is likely that in this case $s^{E}$ will be small in absolute sense. Therefore the excess enthalpy will be regarded as the main component of the excess Gibbs free energy. This is in agreement with the model of strictly regular solutions as described by several authors. ${ }^{29-33}$ Several factors influence this interaction enthalpy: the type of TAA ion; the sodium/silicate ratio.

The interaction enthalpy can be divided into compoundcompound interactions. The $E_{0}$ describes the interaction between one TAA with one silicate ion and the $E_{1}$ is a mixed interaction of three ionic units: one term describing the interaction between two TAA ions with one silicate ion and one term describing the interaction between one TAA ion and two silicate ions.

In Table I the $E_{0}$ and $E_{1}$ are shown. For the coacervates containing TMA bromide the $E_{0}$ decreased and the $E_{1}$ increased with increasing sodium/silicate ratio. In a relative sense, the decrease in $E_{0}$ is more pronounced than the increase of $E_{1}$. On the basis of the interaction between the ions leading to coacervation, this can be explained as follows:

At high sodium/silicate ratio the silicate ions will be present predominantly as monomers with a relatively large charge (1.5-2 units) per silicate ion. This charge can be compensated by sodium and TMA ions. When a large amount of sodium is present, the charge compensation of the silicate ions will occur predominantly by the sodium ions. At small sodium/silicate ratios charge compensation of the silicate ions will be to a larger extent by TMA ions. Therefore the main contribution to the excess Gibbs free energy, the $E_{0}$, decreases with increasing sodium silicate ratio.

In the proportionality constant $E_{1}$ the average charge per silicate ion is reflected: If the silicate is doubly charged, the three ionic interaction will be more pronounced than when the silicate is predominantly singly charged. In the case of sodium/silicate ratio 2:1 the interaction between two TMA ions and one silicate ion will be dominant over the interaction between one TMA ion and two silicate ions. At lower sodium/silicate ratios the domination will be less and the $E_{1}$ will be smaller.

For the different TAA ions $E_{0}$ is nearly constant. The $E_{1}$ however does increase with increasing chain length. In Figure 9 the $E_{1}$ is shown as a function of the square of the enthalpy of hydrophobic hydration, which were calculated by Heuvelsland. ${ }^{34}$ A linear relation is found. This shows that the interaction between two TAA ions and one silicate ion is the major contribution to the $E_{1}$ for these coacervates. The $E_{1}$ values considered here are those of coacervates with sodium/silicate ratio 2:1. As we found for the TMA coacervates with increasing sodium/silicate ratio the

(28) Heuvelsland, W. J. M.; de Visser, C.; Somsen, G. J. Phys. Chem. 1978, 82, 29. Heuvelsland, W. J. M. Thesis, Amsterdam, 1980.

(29) Rowlinson, J. S.; Swinton, F. L. Liquids and Liquid Mixtures, 3rd ed.; Butterworth Scientific: London, 1982; p 171.

(30) Porter, A. W. Trans. Faraday Soc. 1920. 16, 336.

(31) van Laar, J. J.; Lorenz, R. Z. Anorg. Chem. 1925, 145, 239.

(32) Heitler, W. Ann. Phys, 1926, 80, 629.

(33) Hildebrand, J. H. J. Am. Chem. Soc. 1929, 51, 66.

(34) Scatchard, G. Chem. Rev. 1931, 8, 321.

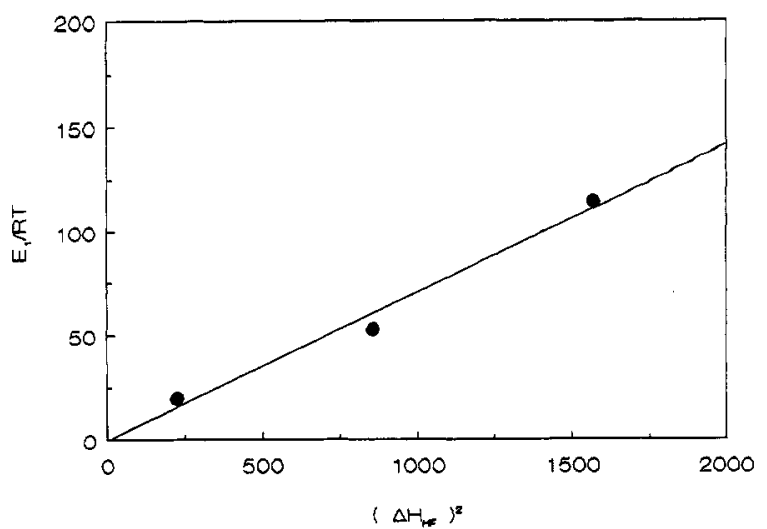

Figure 9. Correlation between the $E_{1}$ of TMA, TEA, and TPA and the square of enthalpy of hydrophobic hydration. ${ }^{27}$

contribution of the first term of the $E_{1}$ is of increasing importance over the second term for 2:1 sodium silicate. The deviations from the line can be due to the errors both in the $E_{1}$ constant and the enthalpy of hydrophobic hydration. The connection between the enthalpy of hydrophobic hydration and the $E_{1}$ suggests that the hydrophobic hydration of the quaternary ammonium ions is of particular importance in the coacervation.

\section{Conclusions}

Coacervation occurs in solutions of TAA bromidesodium silicate-water. The TAA bromide exists predominantly in the upper layer, and the sodium silicate is present mainly in the lower layer. The TAA bromide was nearly stoichiometrically distributed between the two layers. For sodium silicate, deviations are found.

Coacervation can be described using activity coefficients of the two separate salts plus an additional excess Gibbs free energy. The first two terms of the Redlich-Kister equation are used to describe the excess Gibbs free energy. Experimentally determined binodals coincide well with calculated ones. Inaccuracies in this description are caused by deviations from the ternary model and from the formation of double ring silicate structures. One of the terms of the excess Gibbs free energy is linearly dependent on the square of the enthalpy of hydrophobic hydration of the TAA ions.

The coacervation is ascribed to the following mechanisms: TAA ions are hydrophobically hydrated, while silicate ions are hydrophilically hydrated. The structures of the hydration layers are different and the layers cannot overlap. Coacervation can occur in solutions which contain, besides TAA and silicate ions, an additional cation (e.g. sodium) and anion (e.g. bromide). At higher concentrations the TAA and the silicate ions migrate apart and the respective electrical charges will be predominantly neutralized by the other ions present. The sodium will be preferentially in the vicinity of the silicate, while the bromide will be preferentially in the vicinity of the TAA. This leads to two different microstructures. At sufficiently high concentrations, coalescence of these different microspheres will occur and macroscopic phase separation results.

Acknowledgment. This work was sponsored by the Netherlands Ministry of Economics, through a Innovative Research Programme (IOP-catalyses). Dirk Kuyken, John Quaedackers, and Jeroen van Raalte are thanked for their enthusiastic assistance with the experimental work. 